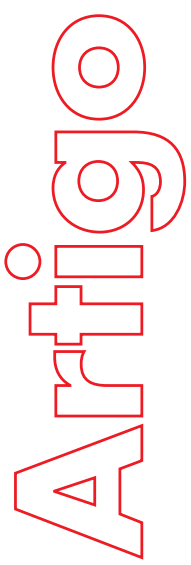

\section{Revista}

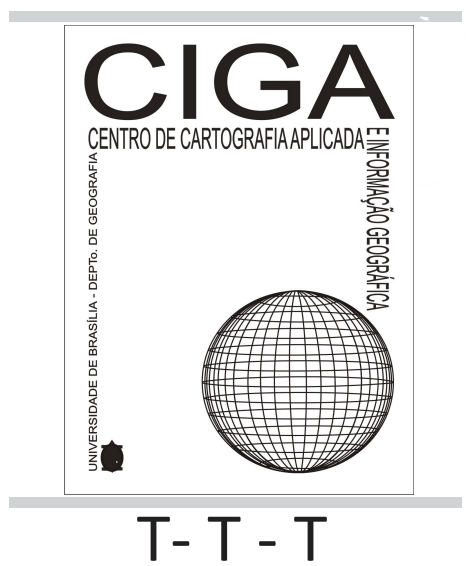

Revista Eletrônica: Tempo - Técnica - Território, V.10, N.2 (2019), 54-80 ISSN: 2177-4366

\section{GEOGRAFIA DOS TRANSPORTES NO DISTRITO FEDERAL: PROPOSTA TECNICA PRELIMINAR PARA O TRANSPORTE PUBLICO}

\section{Gustavo Silveira Tolentino}

p. $54-80$

Como citar este artigo:

Tolentino Silvera, Gustavo.

GEOGRAFIA DOS TRANSPORTES NO DISTRITO FEDERAL: PROPOSTA TÉCNICA

PRELIMINAR PARA O TRANSPORTE PÚBLICO Revista Eletrônica: Tempo - Técnica

- Território, v.10, n.2

(2019),p.54-80 ISSN: 2177-4366.

Disponível em: http://periodicos.unb.br/index.php/ciga/

Este obra está licenciado com uma Licença Creative Commons Atribuição - Não Comercial 4.0 Internacional. 


\title{
GEOGRAFIA E TRANSPORTES NO DISTRITO FEDERAL: PROPOSTA TÉCNICA PRELIMINAR PARA O TRANSPORTE PÚBLICO
}

\author{
Gustavo Silveira Tolentino \\ Geógrafo, mestrando em Geografia pelo Programa de Pós-Graduação em Geografia \\ da Universidade de Brasília (UnB). \\ E-mail: gustavosilveira.t@gmail.com
}

\begin{abstract}
RESUMO: O transporte se constitui como técnica basilar para construção e desenvolvimento do espaço ao passo em que o dinamiza, possibilitando uma ampla integração do território. Na realidade brasileira, o transporte representa grande relevância social e, no caso do Distrito Federal, que abriga a capital do país, apresenta-se como um grande desafio devido às problemáticas geradas em decorrência a valorização do veículo privado em relação ao transporte público. Neste caso, a presente pesquisa tem como objetivo geral apresentar propostas preliminares para o transporte público do Distrito Federal. Referente aos procedimentos metodológicos, a pesquisa foi organizada em quatro etapas: levantamento bibliográfico, levantamento de dados primários e secundários, produção técnica cartográfica junto às saídas de campo para a realização dos mapas e, por último, a construção da proposta preliminar.
\end{abstract}

Palavras chave: Geografia dos Transportes; Proposta Preliminar; Transporte Público; Transporte Privado; Transporte do Distrito Federal.

ABSTRACT: Transport is a fundamental technique for the construction and development of space whilst makes it dynamic, enabling a broad integration of the territory. In the Brazilian reality, public transport represents great social relevance, however, it is configured in a service that is hugely precarious and needs to be reconsidered to meet the needs of the population. The same is true for the Federal District, which houses the capital of the country, a city idealized to service vehicles, and which, as a result, devalued the public and collective transportation system, with several aggregate problems. This research aims to present preliminary proposals for public transportation of the Federal District. Regarding the methodological procedures, the research was organized in four stages: bibliographic survey, primary and secondary data survey, cartographic technical production amongst the field work to the making of the maps and, finally, the construction of the preliminary proposal.

Key-Words: Transport Geography; Preliminary Proposals; Public Transport; Private Transport; Distrito Federal Transport 


\section{INTRODUÇÃO}

O transporte se tornou, ao longo da história da humanidade, um fator intrínseco a realidade do ser humano. Está em todas as ações espaciais e sua influência é primordial para o desenvolvimento de outras atividades da sociedade. Seja para o deslocamento no espaço geográfico ou conectar lugares distintos, o transporte permeia todas as ações espaciais, e a forma pela qual é concebido é reflexo das relações humanas com o espaço, arquitetado através do avanço das técnicas.

De modo geral, a história do transporte passa a ser elaborada através do desenvolvimento técnico sobre o espaço geográfico. Sobre a técnica, se entende como "um conjunto de meios instrumentais e sociais com os quais o homem realiza sua vida, produz e, ao mesmo tempo, cria espaço" (SANTOS, 1996, p.29). Além disso, a utilização desse meio ocasionou o avanço nos modelos de transportes de acordo com as necessidades geomorfológicas e às características do ambiente e, consequentemente, ao desenvolvimento do território.

No Brasil, o transporte teve seu início com as técnicas indígenas e posteriormente se desenvolveu com a chegada dos portugueses e dos povos africanos sobre o território brasileiro. Após esse processo ocorreram diversas mudanças pontuais que podem ser relacionadas a fatos históricos do país, afinal, os sistemas de transporte sempre acompanharam a economia brasileira, como nos períodos do ciclo da cana-de-açúcar, cafeeiro, a extração da borracha, as drogras do sertão entre outros. Já no século XX, o país passou a ter um marco entre esses fenômenos históricos, destacando-se a construção de Brasília como um fator determinante para a mudança do cenário nacional.

Brasília foi construída e efetivada por Juscelino Kubitschek (JK) como "a capital dos veículos" (KUBITSCHEK, 2006). JK tinha como objetivo o desenvolvimento das regiões mais interioranas do território brasileiro e, para isso, chamou atenção para o desenvolvimento da região Centro-Oeste. De fato, a construção da nova capital trouxe mudanças para as regiões do interior do planalto central, entretanto, a cidade já expõe problemas característicos de metrópoles antigas relacionadas ao transporte e a mobilidade urbana. A idealização do veículo privado, entre outros fatores ao longo da história do Distrito Federal (DF), ocasionaram uma malha urbana que expõe a fragmentação do sistema de transporte. 
Assim, levando em consideração os aspectos ressaltados, a presente pesquisa tem como objetivo apresentar propostas preliminares para o transporte público do Distrito Federal. Para analisar a importância do transporte pela ótica da Geografia, é necessário elencar conceitos teóricos que dão suporte ao entendimento desta técnica sobre o território e, para tanto, se faz essencial para o desenvolvimento deste trabalho. Neste caso, a primeira etapa do artigo consiste em apresentar os procedimentos metodológicos. A segunda parte busca apresentar, de maneira breve, teorias que embasam o pensamento da Geografia dos Transportes. Já a terceira etapa apresenta as possíveis propostas preliminares para o sistema de transporte público.

É importante ressaltar que esta pesquisa é um resumo de uma obra de conclusão de curso que passou por diversas alterações para adequações deste artigo. Neste caso, serão abordados, de maneira breve, os principais conceitos e avanços sobre uma possível proposta técnica prelimitar para o transporte público do Distrito Federal. É oportuno apontar que a Geografia se apresenta como essencial para o desenvolvimento do transporte através da gestão territorial, assim sendo, o estudo busca compreender o sistema de transporte público e quais apontamentos podem ser apresentados.

\section{METODOLOGIA}

Este trabalho tem como tema central a Geografia dos Transportes e as problemáticas enfrentadas no sistema de transporte público do Distrito Federal. A importância do estudo se revela por colocar em evidência a realidade vivida pela população em função deste serviço em sua dimensão geográfica. Nesta perspectiva, trata-se de uma pesquisa qualitativa, quando utilizado de conceitos relacionados às ações humanas sobre o território, e quantitativa, por meio da utilização de dados que estruturam gráficos e representações cartográficas.

No que diz respeito à estrutura teórica utilizada na pesquisa, destaca-se a temática do transporte como área interdisciplinar, tendo participação de outras áreas como a Engenharia, Sociologia, História, Economia entre outras ciências. Entretanto, a base conceitual utilizada para a pesquisa se baseia exclusivamente na Geografia, por ser tratar da ciência que estuda o território.

Nesse aspecto, foi escolhido o método de pesquisa descritiva, pois se entende que esse procedimento metodológico enfatiza a preocupação em identificar os fatores que determinam a ocorrência do transporte e seus fenômenos sobre o território. Além disso, este modelo é voltado 
para pesquisas que "mais aprofunda o conhecimento da realidade, porque explica a razão, o porquê das coisas" (GIL, 2012, p.28), dando a possibilidade de compreender a organização dos sistemas de transportes sobre o território do Distrito Federal.

Os procedimentos metodológicos foram divididos em três etapas. A primeira atentouse a delimitação do recorte espacial da pesquisa. Neste caso, para a realização do estudo, foi necessária a compreensão do sistema de transporte do Distrito Federal, categorizada como escala geral (1:100.000). A escolha dessa escala se deu pelo entendimento de apresentar uma proposta que envolva todo o DF.

Todavia, para o desenvolvimento da pesquisa, sentiu-se a necessidade apresentar uma regionalização de impacto do transporte. À vista disso, foi realizada pesquisas de possíveis propostas já apresentadas, contudo, não foi possível encontrar nenhum estudo referente ao tema. Nesta situação, foi elaborada uma proposta de regionalização do DF de acordo com o impacto do transporte nas Regiões Administrativas (RA's), tendo como produto final a elaboração de um mapa (figura 1). A escolha dessa regionalização foi desenvolvida para a classificação dos modais de transportes. Vale destacar que sua divisão foi realizada no entendimento nas áreas de impacto do transporte sobre o território do DF.

Definindo o recorte espacial, sentiu-se a necessidade do suporte teórico para o prosseguimento do trabalho. Nesse sentido, inicialmente, buscou-se o levantamento bibliográfico pertinente aos conceitos gerais da pesquisa. Após a investigação das obras conceituais, percebeu-se a importância de compreender o planejamento de transportes sobre o território do Distrito Federal.

Após a definição das etapas anteriores, foi importante o levantamento de dados para o desenvolvimento do estudo. A pesquisa conta com dados primários e secundários. Para a aquisição dos dados primários, foram observados em um período de um mês, os principais pontos de engarrafamento dentro da área de recorte da pesquisa. Inicialmente, os dados coletados foram obtidos através da realização de saídas de campo. As saídas de campo consistiam na utilização do transporte público durante o período de pico, formando de forma sistematizada, um banco de dados que posteriormente foi comparado com as análises de engarrafamento em tempo real através da plataforma Google Maps. Já o conjunto de dados secundários foi estruturado a partir de informações obtidas através de dados oficiais do Governo do Distrito Federal (GDF), Instituto Brasileiro de Geografia e Estatística (IBGE), GeoPortal do 
Distrito Federal, Moovit e Companhia de Planejamento do Distrito Federal. A coleta de dados secundários permitiu a realização dos produtos cartográficos, associado às informações de campo, que deram estruturação com a parte teórica à prática da pesquisa.

\section{Figura 1: Mapa da região de impacto de transporte}

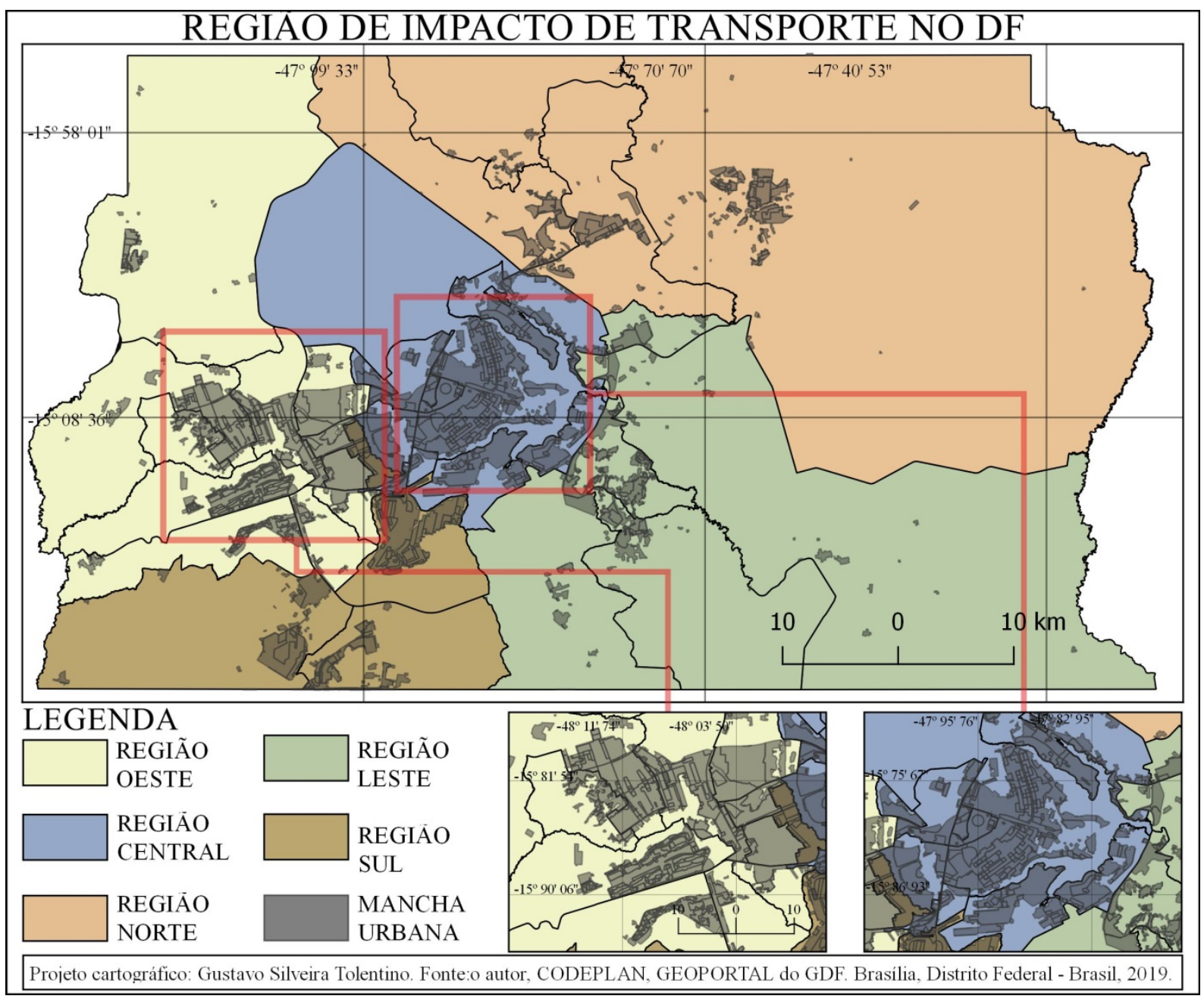

Elaboração: Gustavo Tolentino, 2019. Fonte: GeoPortal do GDF e CODELAN (2019)

\section{RESULTADOS}

Mesmo com o crescente número de pesquisas relacionadas ao transporte ao longo do século XX, são poucos os geógrafos brasileiros que destacam a temática como ramo de pesquisa da Geografia. Segundo Silveira (2010) a "negligência está custando caro à Geografia" devido ao grande processo de interação que a globalização vem apresentando nos últimos anos. Porém, 
é importante ressaltar a existência de pesquisas, mesmo dado de maneiras difusas, relacionados ao transporte. .

Quando tocante ao transporte, a linha de pensamento da Geografia se divide em duas vertentes: a Geografia da Circulação, e a Geografia dos Transportes. Tendo suas origens conceituais na Geografia Clássica com Friedrich Ratzel e Vidal de La Blache, ambas as áreas de desenvolvimento vem sendo inexploradas ao longo dos anos, porém, alguns geógrafos como Milton Santos, Márcio Silveira, Regina Celeste entre outros, citam a temática de transportes em suas análises de pesquisas.

De maneira cronológica, os estudos surgiram no final do século XIX, início do século XX e logo passou por diversas transformações políticas, filosóficas e sociais impostas pelo contexto histórico. Devido às transformações ocorridas nesse período, vão surgindo dúvidas sobre as diferenças entre "Geografia da Circulação" e "Geografia dos Transportes". Nesse sentido, Silveira (2010) alega que "na visão clássica há diferenciações”, entretanto com o passar do tempo e com a tamanha proporção da Geografia dos Transportes, não é mais possível levantar comparações entre esses termos:

\begin{abstract}
Logo, de imediato, o que se refere à Geografia dos Transportesll e a Geografia (Geral) da Circulação? Chegamos à conclusão, como será demonstrado, que na visão clássica há diferenciações, todavia, com o decorrer do tempo, principalmente com o advento do termo Geografia dos Transportes, não foi mais permitido a diferenciação entre um termo e outro, ou seja, tornou-se uma simples metáfora orgânicall (PACHECO, 2001). Nesse sentido, tanto uma expressão como a outra passaram a redundar o estudo das vias e meios de transportes (sistemas de movimento), o ato de transportar mercadorias, pessoas e informações e as consequências sobre o espaço e/ou a própria produção do espaço. (SILVEIRA, 2010 p.8 e 9)
\end{abstract}

As diferenças entre a Geografia da Circulação e a Geografia dos Transportes são baseadas nas abordagens tocantes aos meios e infraestrutura de transportes. Para Silveira (2010) os termos devem ser analisados em suas devidas perspectivas espaciais, deste modo "ambas, devem ser entendidas num sentido bastante amplo e integradas: circulação numa forma totalizadora e transporte em seu caráter mais específico (associado às lógicas de planejamento urbano e regional)" (SILVEIRA, 2010, p. 7). Entretanto, Pacheco (2001) alega que, na maioria das vezes, os estudos realizados por essas duas vertentes de pensamento apresentam visões de maneiras isoladas e não como um sistema como um todo (PACHECO, 2001, p. 25).

Diante deste cenário, entende-se a necessidade do aprofundamento dos estudos referentes ao transporte. Os arcabouços conceituais tanto da Geografia da Circulação como Geografia dos Transportes deixam a desejar devido à evolução o dos sistemas de transportes ao 
longo dos anos, que passam a ser cada vez mais intrísecos ao território. Deste modo, compreende-se a técnica como uma das principais forma de análise a fim de compreender a relação que o homem estabelece entre o meio através da técnica de transporte, pois entende-se às técnicas como "um conjunto de meios instrumentais e sociais, com os quais o homem realiza sua vida, produz e, ao mesmo tempo, cria espaço" (SANTOS 1996, p.29).

No tocante às técnicas de transportes no DF, compreende uma formação dada de maneira desigual no tempo e no espaço. A cidade de Brasília se constiuiu através do planejamento urbano, contudo, foi uma das poucas exceções entre as demais cidades que surgiram através do crescimento urbano descontrolado. Esse cenário influenciou para a complicação do sistema de transporte da Capital Federal, que passou a integrar uma estrutura viária fragmetada. Não obstante, o meio metroviário não atende as necessidades e espectitativas da população que, por sua vez, busca meios de transportes privados a fim de atender as demandas de deslocamento impostas.

\section{PROPOSTAS PRELIMINARES PARA O TRANSPORTE PÚBLICO DO DISTRITO FEDERAL}

Abordar propostas técnicas referentes ao transporte público requer atenção devido à complexidade apresentada pela dinâmica urbana. Para tanto, a compreensão das relações no espaço urbano é essencial para a fundamentação de possíveis análises. Referente a isso, entende-se o espaço urbano como apontado por Anjos:

\footnotetext{
Buscamos tratar o espaço urbano numa perspectiva dinâmica, onde tomamos como referência o crescimento da cidade, um dos componentes básicos da urbanização. É um processo espacial com dimensão temporal, onde a compreensão da atualidade integra as mudanças do passado e o potencial de variações para o futuro próximo. Dessa maneira, entendemos a dinâmica espacial como um conjunto de eventos intercortados e estabelecidos, onde as suas interações refletem a estrutura da cidade. (ANJOS 2008, p.26)
}

Nesse sentido, infere-se que o transporte urbano está associado às mudanças da dinâmica da cidade e, no caso da metrópole brasiliense, percebe-se essa problemática no desenvolvimento de "um tecido urbano socialmente fragmentado e espacialmente polarizado" (FERREIRA; PENNA 1996 p.190) e, além disso, vem apresentando "os mesmos grandes desafios que se colocam para as cidades tradicionais que se modernizaram" (FERREIRA; PENNA 1996, p.189). 
Nessa perspectiva, em virtude do cenário do transporte do DF, entende-se a necessidade de novas intervenções para o desenvolvimento da mobilidade urbana. Por essa razão, o planejamento de transportes passa a ser pauta essencial para a evolução de intervenções sobre um território já consolidado. É importante destacar a existência de diversos trabalhos referentes à temática debatida, todavia, são pesquisas técnicas de âmbito geral ou, particulares a engenharia dos transportes. Não cabe aqui, nesta pesquisa, o levantamento exaustivo referente a essas obras, pois, busca-se apresentar uma proposta preliminar a partir dos conhecimentos geográficos.

\section{Características do território}

É pertinente considerar alguns fatores, conforme apresentando por Campos (2013), para o desenvolvimento do planejamento em transporte. Entre eles, destacam-se o impacto da densidade urbana, a concentração de empregos, a migração pendular e os vetores de expansão e as áreas de congestionamento. Essas análises são realizadas no intuito de alcançar o objetivo do planejamento de transportes, que é "definir medidas ou estratégias para adequar a oferta de transportes com a demanda existente ou futura" (CAMPOS 2013, p.1).

\section{Densidade urbana}

A importância do estudo da densidade demográfica é refletida nas análises espacialmente representadas sobre o território. Além disso, "a densidade urbana é um dos mais importantes indicadores e parâmetros de desenho urbano a ser utilizado no processo de planejamento e gestão dos assentamentos humanos." (2011, p.14 apud CODEPLAN 2017,)

A densidade urbana, como apresentada no mapa a seguir (figura 2), destaca alta taxa de nas RA's do Varjão (142,27 hab./ha), Candangolândia (137,38 hab./ha), Ceilândia (129,94 hab./ha) e Recanto das Emas (117,88 hab./ha). Enquanto isso, as menores taxas registradas se encontram nas RA's SIA (1,08 hab./ha), Park Way (3,50), Lago Sul (6,66 hab./ha) e Jardim Botânico (8,91 hab./ha). É importante ressaltar que o Varjão e a Candangolândia apresentamse fora da curva, devido ao pequeno tamanho do território, comparado a outras cidades.

Olhando de maneira geral, nota-se que a densidade urbana é muito grande na região oeste do DF, com concentração nas RA's Ceilândia, Taguatinga, Samambaia, Recanto das Emas e Riacho Fundo II. Somando a quantidade de pessoas entre essas cidades é possível encontrar mais de um milhão de habitantes que residem nessas cidades. Na região norte do DF, 
as cidades de Sobradinho I e II, Planaltina e Fercal comportam média densidade e ao total, congregam mais de 350 mil pessoas. Na região Sul a densidade é média, contudo, o número de habitantes passa de 300 mil. (PDAD 2017). Já a região central do DF apresenta baixa e média densidade demográfica.

\section{Figura 2: Mapa da densiade Urbana do Distrito Federal}

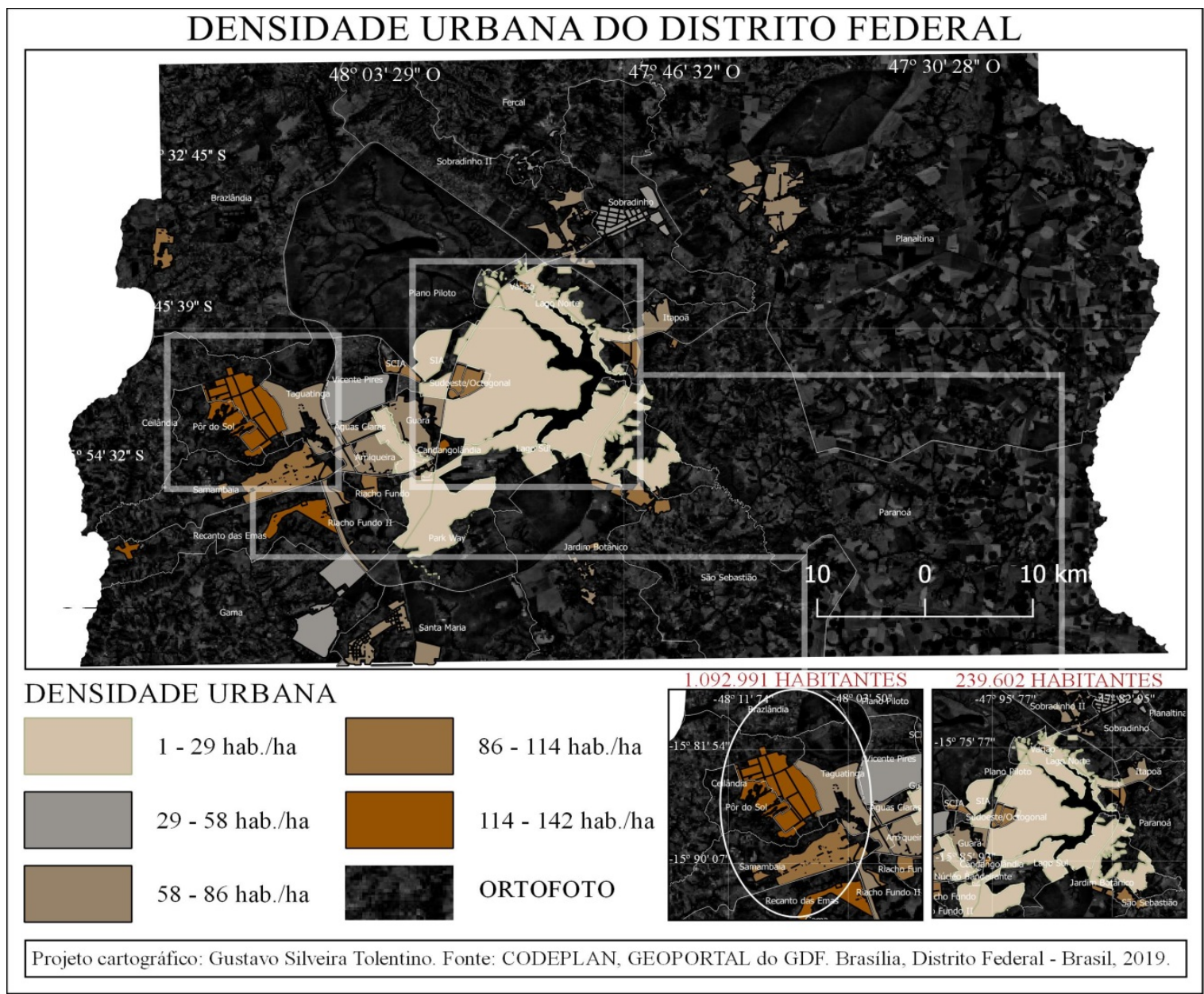

Elaboração: Gustavo Tolentino, 2019. Fonte: GeoPortal do GDF e CODELAN (2019)

Mesmo demonstrando menor densidade urbana, a RA Plano Piloto concentra 41\% dos empregos do DF, em seguida de Taguatinga com 8,3\% e Ceilândia com 6,3\% como apresentado na figura 3. A concentração de emprego na região ganha destaque devido à quantidade de pessoas que precisam migrar para a cidade diariamente, ocasionando assim o aumento de transporte entre essas cidades. 


\section{Migração pendular e população abrangida por transporte frequente}

Em resultado da concentração de empregos no Plano Piloto, o DF passa a ter recorrentemente o deslocamento de pessoas sobre o seu território. Além do trabalho, a procura por educação, concentrada no Plano Piloto e em Taguatinga, também exige o aumento diário de circulação. Esses fatores, entre outros, são determinantes para o aumento da migração pendular da capital federal.

\section{Figura 3: Distribuição do local em que as pessoas exercem seu trabalho principal}

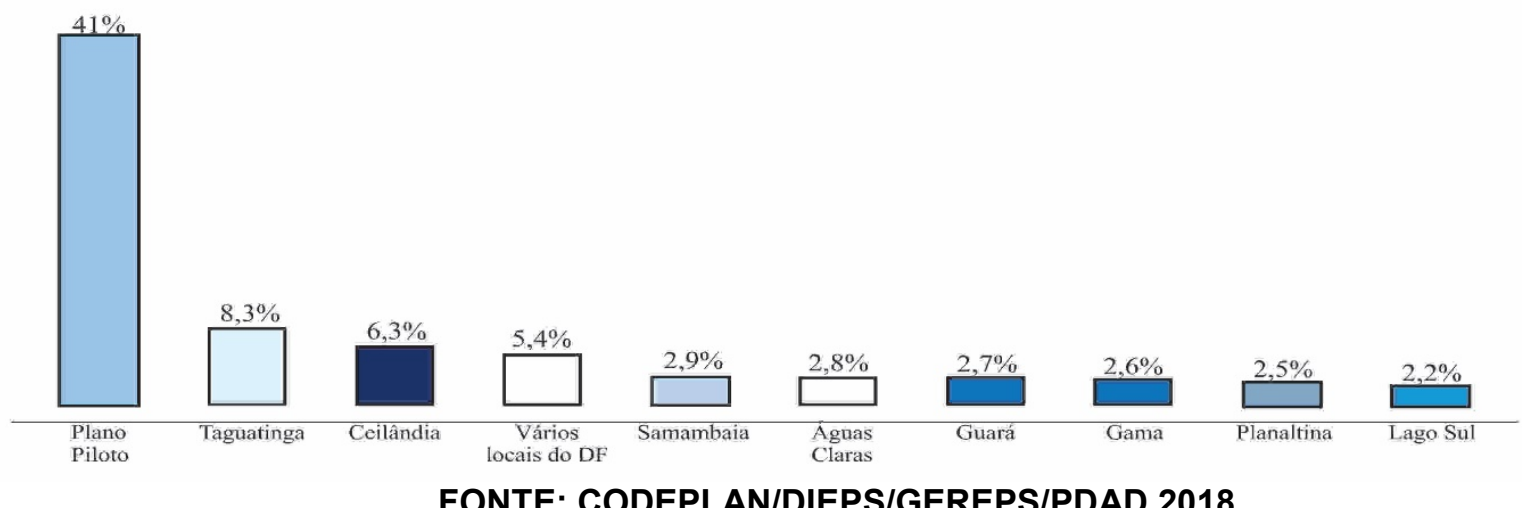

Segundo os dados do PDAD (2018) 1.261.222 pessoas se deslocam diariamente para o exercício do trabalho principal. Quando especializado esses dados sobre o território do DF (figura 4), percebe-se grande número de deslocamento das RA's no sentido do Plano Piloto em seguida de Taguatinga. O mapa evidencia a região sul e oeste como a segunda maior concentração do fenômeno da migração entre as RA's, dando realce a dinâmica entre essas cidades. Em relação às demais RA's, quase 80 mil pessoas saem da Ceilândia, tendo principal destino o Plano Piloto (87.080 pessoas) e os demais se concentram entre Taguatinga, Samambaia e Águas Claras. Dentro desse cenário de migração pendular, $47 \%$ da população utiliza o carro como meio de transporte, seguido por 38\% que usam o ônibus e 3,7 reportam o uso do metrô entre outros veículos como motocicleta $(2,1 \%)$ e a bicicleta $(2,1 \%)$ enquanto $14,5 \%$ vão a pé (PDAD 2018).

Já a migração pendular ocasionada pela educação apresenta um fluxo migratório inferior a demanda de trabalho, justificável pela quantidade de escolas nas RA's e, em decorrência de ser um grupo inferior de pessoas trabalhando. Segundo o PDAD (2018), do total de 755.662 estudantes do DF, 20,5\% declararam que estudam no Plano Piloto, em seguida da Ceilândia $(13,3 \%)$ e Taguatinga (12,1\%). Os dados, quando especializados sobre o território do DF, 
apresentam uma dinâmica de circulação em volta da temática escolarização (figura 5). Assim como na atividade de serviço, as RA's do Plano Piloto, Ceilândia e Taguatinga recebem maior número de estudantes de todo o DF número de distribuição de escolas. Porém, vale destacar que os dados referentes à Ceilândia são elevados devido ao alto número populacional, ocasionando assim, a quantidade de alunos residentes na própria cidade.

Figura 4: Mapa da migração pendular por demanda de trabalho no Distrito Federal

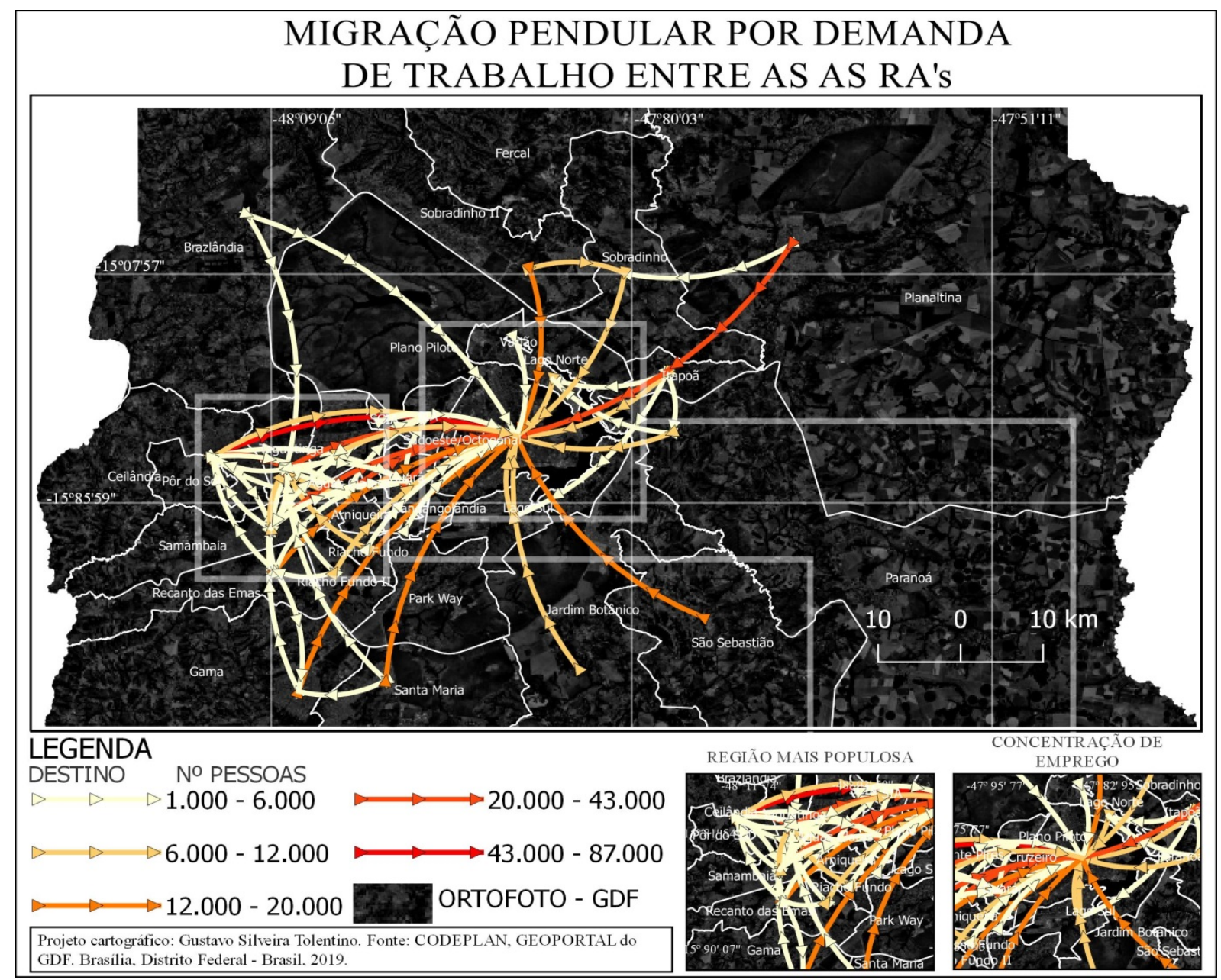

Elaboração: Gustavo Tolentino, 2019. Fonte: GeoPortal do GDF e CODELAN (2019)

Tocante ao meio de transporte entre a escola e o trabalho, $35,8 \%$ dos estudantes alegaram que vão a pé, enquanto $27,6 \%$ vão de carro, seguidos por $23,7 \%$ que vão de ônibus e $6,9 \%$ que utilizam o transporte escolar privado entre outros como metrô $(1,4 \%)$ e bicicleta $(1,1 \%)$. Somando a porcentagem de alunos que utilizam meios de transportes, contabilizam ao total de $59,3 \%$ que precisam do mesmo no DF. 
Contudo, mesmo com grande movimento pendular, a população abrangida por transporte coletivo não alcança toda a mancha urbana da cidade. Segundo a CODEPLAN (2018), "a abrangência do transporte coletivo, em vinte e duas RAs, chega a uma cobertura espacial acima de 50\% (Planaltina), chegando a quase 100\% do território (Cruzeiro). Enquanto, apenas nove RAs tem uma cobertura abaixo de 50\%, o que perfaz uma média no Distrito Federal de 72\%" (CODEPLAN 2018, p.21). A figura 50 demonstra essa abrangência entre as RA's.

Essa problemática, quando associada à migração pendular, realça a consolidação do uso do veículo privado. Como resultado, a mobilidade urbana da cidade fica sobreposta entre o transporte coletivo, utilizado para quem tem fácil acesso a esse serviço e, o transporte privado, usufruído para quem tem condição e para os que não têm outra escolha a não ser o uso desse meio de deslocamento. Quando associado esses tipos de transporte, à distância a ser percorrida fortifica o movimento pendular e em consequência, percebe-se a ocorrência do aumento de engarrafamento das principais vias da cidade.

\section{Figura 5: Mapa da migração pendular por demanda de trabalho no Distrito Federal}

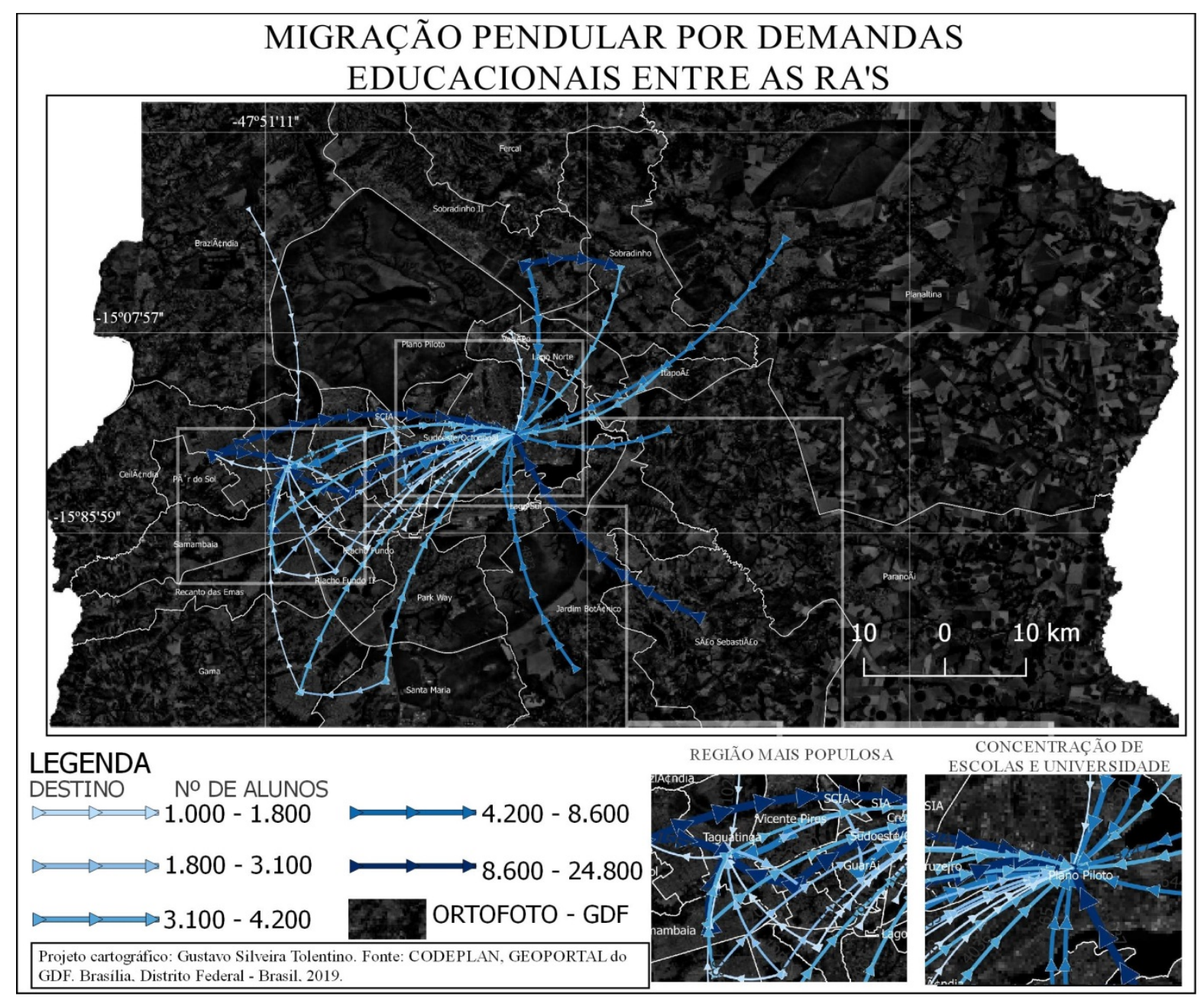

Revista Eletrônica: Tempo - Técnica - Território, V.10, N.2 (2019), 54:80 - ISSN: 2177-4366 
Elaboração: Gustavo Tolentino, 2019. Fonte: GeoPortal do GDF e CODELAN (2019)

\section{Vetores de expansão}

O último e um tanto importante fator a ser analisado são os vetores de expansão do território do DF. De acordo com GERMANI (1970), como ponto de partida é necessário conhecer os "desejos" de deslocamento da população, e então estabelecer relações entre o número de viagens realizadas, de modo que, quando projetadas, permitam inferir os desejos de deslocamentos no futuro.

Nesse sentido a CODEPLAN (2017) expõe os possíveis avanços urbanos do DF. O Zoneamento Econômico do Distrito Federal (ZEE-DF) é um instrumento da Política Nacional do Meio Ambiente que se concretiza como legislação local e que tem por objetivo, em linhas gerais, viabilizar o desenvolvimento dos territórios a partir da compatibilização entre conservação ambiental e desenvolvimento socioeconômico. O relatório do ZEE buscou encontrar insumos e objetivos a partir da consulta aos técnicos governamentais para modelagem final das zonas e subzonas. A espacialização do cenário tendencial consiste em expressar territorialmente, tanto quanto possível, as principais tendências apontadas que tenham implicações na organização e transformações do espaço (CODEPLAN 2017).

Segundo a CODEPLAN a avaliação das tendências do uso e ocupação do solo considerou os vetores de expansão e adensamento urbano, as estratégias de ordenamento territorial do PDOT. Foi feita uma análise geral das tendências territoriais do DF a partir dos principais eixos viários, entendidos como vetores de crescimento urbano. A seguir se apresenta o resumo e um mapa (figura 6) do cenário territorial tendencial para o DF, identificado a partir dos principais vetores de crescimento urbano, associado aos eixos viários:

1) No Eixo da BR-040/DF-001/DF-003, estão os núcleos urbanos mais populosos do Distrito Federal (Taguatinga, Ceilândia, Samambaia, Recanto das Emas, Riacho Fundo, Gama e Santa Maria) e alguns dos municípios da Área Metropolitana de Brasília (AMB) que mantêm uma relação mais intensa com o DF, como Novo Gama, Cidade Ocidental e Valparaíso. As tendências são a progressiva conurbação e o adensamento progressivo deste eixo com impactos no padrão da mobilidade urbana, descaracterização das áreas rurais e impactos nos recursos naturais, notadamente nos pequenos mananciais de abastecimento público ainda ativos nesta área.

2) No Eixo da BR-060, a tendência são a consolidação e o adensamento progressivo das áreas urbanas ao longo deste eixo dentro do DF, as expansões de Engenho das Lajes e do Setor Habitacional Água Quente com a formação de uma possível conurbação que aproxime Samambaia de Santo Antônio do Descoberto. 
3) No Eixo da BR-070, a tendência é a conurbação progressiva entre Ceilândia e Águas Lindas - GO, considerando a contínua criação de loteamentos neste município que faz com que o seu crescimento urbano, explosivo no final da década de 1990, ainda se mantenha elevado e continue atraindo populações do DF. Taguatinga e Ceilândia tendem a aumentar sua influência na atração de empregos, comércio e serviços.

4) No Eixo da BR-010/DF-003, a tendência é que, pelos melhoramentos e ampliações viárias que estão sendo executadas na saída norte, este seja um vetor cada vez mais forte de ocupação da porção leste do DF, acentuando a expansão e o adensamento urbanos no entorno de Sobradinho e Planaltina.

5) No anel viário definido pela DF-001, o chamado "arco de ocupações irregulares do Distrito Federal", a tendência são a expansão e adensamento continuados das ocupações irregulares (regularizáveis e não regularizáveis), porém com um ritmo mais lento do que em outras áreas do DF, considerando o perfil de baixa densidade das ocupações associado à renda média-alta da população atual. Contudo, nas áreas de média-baixa renda, as tendências são a expansão e o adensamento das ocupações já consolidadas e o surgimento de ocupações irregulares, se não controladas.

\section{Figura 6: Principais vetores de Expansão Ubana do DF}

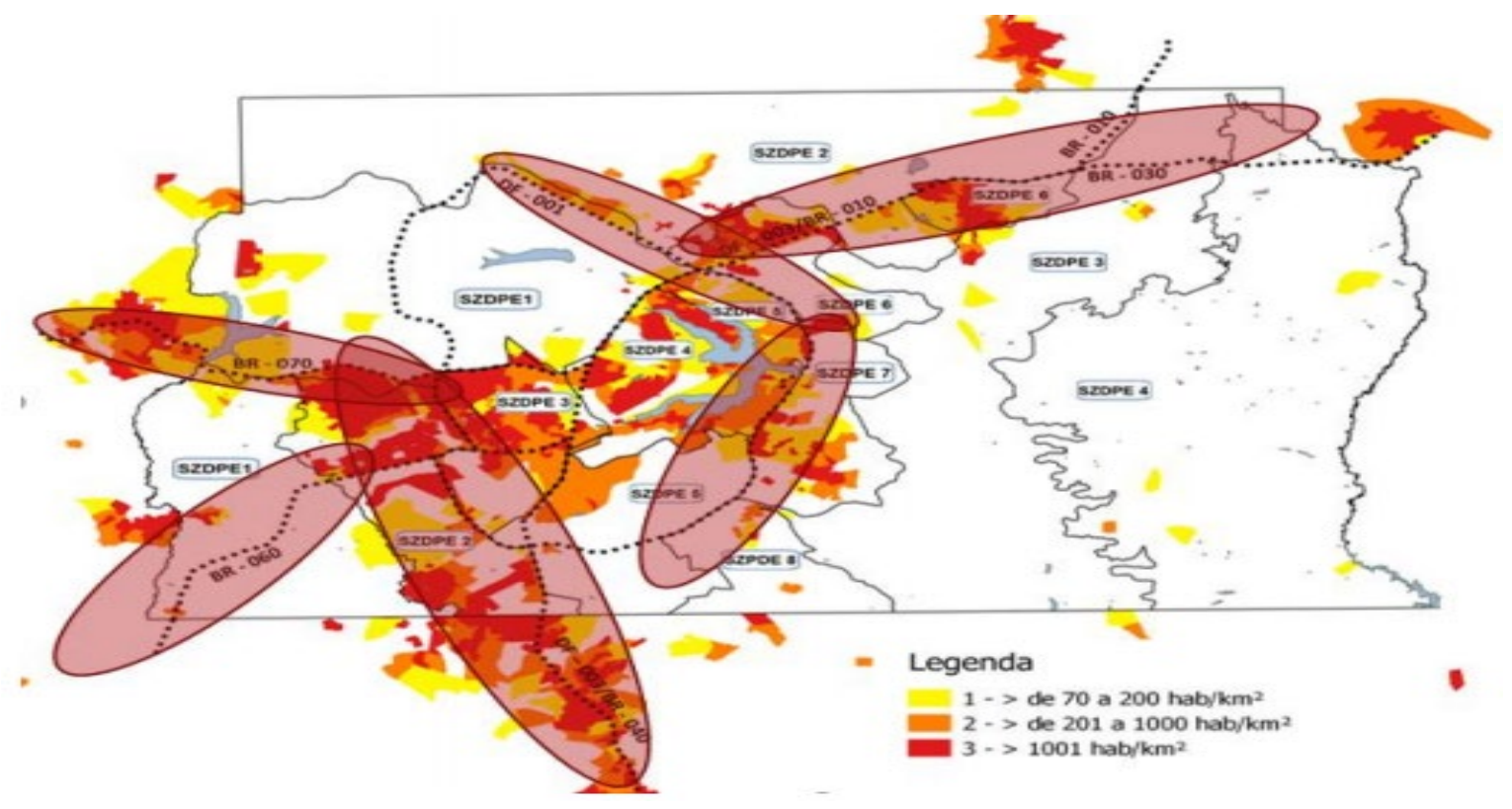

Elaboração: CODEPLAN. Fonte: CODEPLAN (2010)

\section{Possíveis propostas}

As propostas que serão apresentadas são embasadas no entendimento que o espaço urbano é dinâmico, apresentando características e demandas diferentes de acordo com localização e, não necessariamente, seguindo a mesma ordem dos fatores ditos anteriormente. Nesse sentido, os meios de transportes públicos que terão maior enfoque nesta pesquisa são o BRT e o VLT. O metrô, por sua vez, teve uma proposta de grande consistência apresentada por 
meio relatório do Plano Diretor de Transportes e Mobilidade do Distrito Federal (PDTT/DF), acreditando assim, a importância de mantê-la como parte do projeto.

A fundamentação dessa decisão se deu pelo custo e benefício, levando em consideração também os prazos para implantação de cada modal de transporte. Referente aos prazos, estimase que o BRT demore em média de 24 a 36 meses para sua execução. Já o VLT demanda cerca de 40 a 60 meses, enquanto o metrô leva quase o dobro de tempo do VLT e o triplo do BRT, demandando cerca de 5 a 9 anos.

No que diz respeito aos gastos, calcula-se, além do valor da construção, o quanto um modal de transporte gasta em manutenção com a capacidade de demanda. Segundo Jaime Lerner (2009), para cada $1 \mathrm{~km}$ de metrô construído, se gasta em média R \$201,0 milhões de reais, podendo alcançar até $\mathrm{R} \$ 500$ milhões (IPEA 2019). Na mesma metragem, calculasse o preço do VLT em cerca de R\$ 40,4 milhões e R\$ 11,1 milhões para o BRT (LERNER 2009, p.32). A tabela 1 resume os prazos e custos de acordo com a modalidade descrita anteriormente.

As novas estruturas apresentadas são pensadas em prazo de implantação de cinco até quinze anos, contudo, são levadas em consideração as mudanças de urgências como apresentadas a seguir.

Tabela 1: Prazos e valores de acordo com a modalidade de transporte

\begin{tabular}{c|c|c|c|c|c|c}
\hline \multirow{2}{*}{ Etapas } & \multicolumn{2}{|c|}{ METRÔ } & \multicolumn{2}{|c|}{ VLT } & \multicolumn{2}{c}{ BRT } \\
\cline { 2 - 7 } & Prazo & Custos & Prazo & Custo & Prazo & Custo \\
(anos) & (R \$ milhões) & (anos) & $(\mathrm{R} \$$ milhões) & (anos) & (R\$ milhões) \\
\hline Projeto básico & 1 & 4,5 & 1 & 1,5 & 0,5 & 0,3 \\
\hline Financiamento & 2 & 0,5 & 2 & 0,5 & 0,5 & 0,2 \\
\hline $\begin{array}{c}\text { Projeto } \\
\text { executivo }\end{array}$ & 1 & 5,0 & 1 & 2,0 & 0,5 & 0,5 \\
\hline $\begin{array}{c}\text { Implantação } \\
\text { TOTAL }\end{array}$ & 5 & $2.000,0$ & 2 & 400,0 & 1 & 110,0 \\
\hline
\end{tabular}

FONTE: Jaime Lerner, 2009

\section{Bus rapid transit - BRT}

O BRT é um sistema de transporte público coletivo, construído com a finalidade de transportar passageiros sobre o espaço urbano de uma maneira mais rápida. Sua infraestrutura 
é construída de forma exclusiva a atender a capacidade de circulação sem interrupção externas como congestionamento de carro ou a disputa de espaço com outros veículos. Diferente do ônibus normal, o BRT (figura 7) chama atenção devido à modernização do serviço prestado, como maior capacidade, conforto e estabilidade de sua operação.

\section{Figura 7: Foto do corredor segregado para o BRT em Brasília}

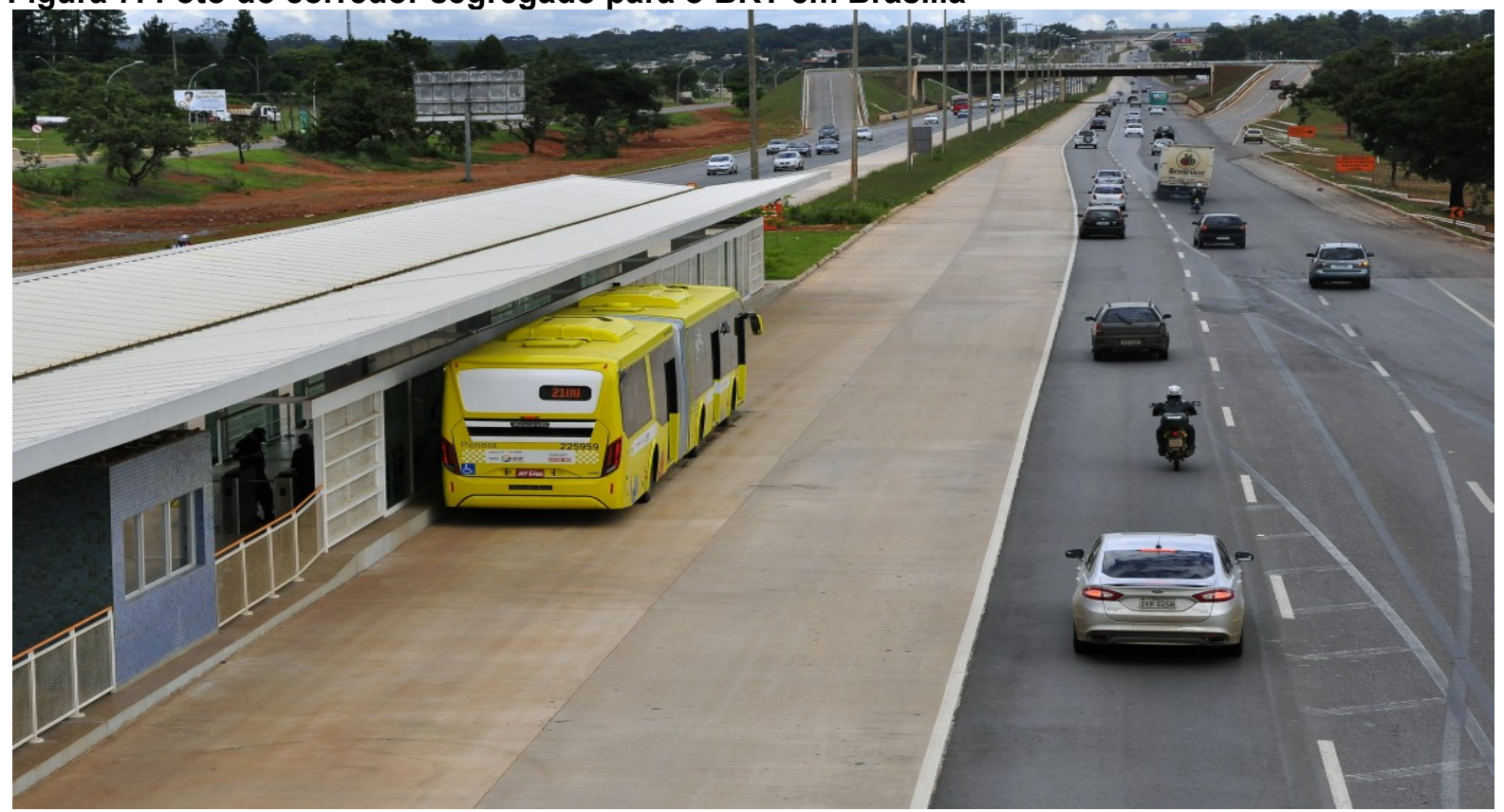

Foto: Mariana Gil / EMBARQ Brasil

São muitas as vantagens apresentadas pelo sistema de transporte do BRT. Para os passageiros, pode-se pontuar que esse meio de transporte é mais vantajoso devido ao curto tempo de espera entre um veículo e o outro e, além disso, o trajeto é realizado de maneira mais veloz. No que diz respeito ao benefício de sua implantação, o custo de construção e operação é o mais baixo quando comparado a outros modais de transportes, como apresentado anteriormente. Além disso, é uma obra de intervenção mais rápida, podendo ser construída em poucos anos e exercendo grande função na mobilidade urbana da cidade.

Diante dos aspectos positivos referentes ao BRT, acredita-se que sua expansão seria fundamental para a melhora do desenvolvimento do transporte público da cidade. O mapa a seguir (figura 8) apresenta uma possível proposta preliminar do sistema de transporte do BRT sobre o território do DF. 
Figura 8: Mapa da proposta de expansão do sistema do BRT

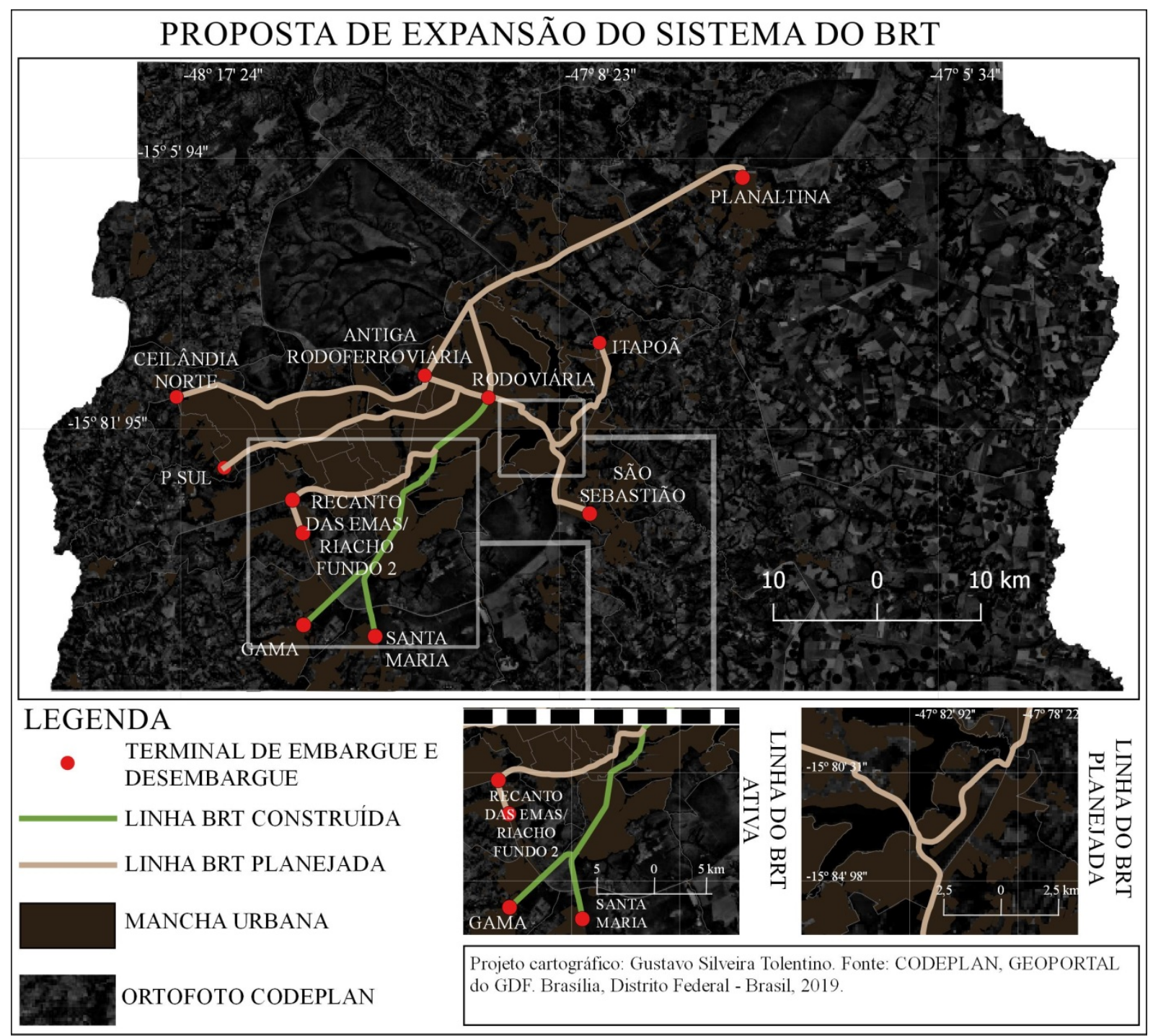

FONTE: GEOPORTAL GDF, CODEPLAN E O AUTOR.

A proposta apresentada para a região sudoeste inclui a construção de um conjunto de corredores interligados de BRT que realizarão o transporte de pessoas através das principais vias da cidade. Ao total, essa área comporta três linhas, sendo duas na Ceilândia, mas especificamente na DF-95 ou Via Estrutural e, na via Elmo Serejo. Enquanto isso, a outra linha tem origem no encontro do Recanto das Emas com o Riacho Fundo II, com prosseguimento na BR-060 e a EPNB.

Acredita-se ser necessária a construção de três corredores de BRT nessa região devido à alta densidade urbana e, consequentemente, ter a maior concentração de pessoas de todo o DF. As linhas foram projetadas de acordo com a demanda da população, visando ocupar as principais áreas de congestionamento. A escolha do corredor na Estrutural visa compensar o 
fluxo de passageiros da região e do entorno, mas especificamente da cidade de Águas LindasGO e, além do mais, a proposta alcança o extremo norte da Ceilândia. Já a Elmo Serejo foi idealizada devido a quantidade de pessoas que circulam sobre essa via, ocasionado posteriormente o agravamento do congestionamento no centro de Taguatinga. Por último e um tanto necessário é o trajeto originado entre o Recanto das Emas e Riacho Fundo II, recebendo assim, alto número de passageiros com destino ao Plano Piloto, Taguatinga, Ceilândia entre outras cidades do DF.

No que diz respeito à região norte, entende-se a necessidade de desenvolvimento de novos meios de transporte além do ônibus. Com isso, o corredor exclusivo do BRT foi pensado na ligação da cidade de Planaltina e Sobradinho. Por mais que a área analisada comporte apenas três RA's, compreende-se o alto nível de circulação sobre a BR-020, gerando também o congestionamento na entrada e saída do eixo norte e, nos trajetos próximos a Sobradinho. Acredita-se que somente uma linha seja suficiente, pois ela é conectada com outros destinos além do Plano Piloto, regiões até então carentes de conexões diretas entre elas.

A região nordeste recebe as RA’s do Itapoã, Paranoá, São Sebastião e Jardim Botânico. Nota-se alto grau de complexibilidade por ser uma região com relevo acentuado e com grande área de congestionamento. Nesse sentido, o planejamento idealizado para a região é a construção de dois corredores de BRT com origem nas cidades do Itapoã e São Sebastião, que se encontram na chegada da ponte JK, com destino ao Plano Piloto. A linha com origem em São Sebastião foi planejada para o incentivo do uso do transporte público na cidade e, na RA Jardim Botânico, tendo em vista a alta taxa de motorização entre os moradores. Já a linha do Itapoã, precisa ter maior extensão devido à ausência de uma ponte que conecta seu território com o Lago Norte e a Asa Norte. Nesse caso, entende-se ser mais rápida a construção da malha viária do BRT nesse percurso do que a idealização da ponte, já prevista pelo GDF.

A região sul, formada pelas RA’s do Gama, Santa Maria e Park Way não teve nenhuma proposta apresentada, pois é a única região que já recebe dois corredores do BRT. Nesse caso, compreendeu-se que não seria necessária a expansão do modal devido à eficiência do transporte já prestado. Entretanto, é importante apresentar o encontro desses dois corredores com a linha de origem no Recanto das Emas e Riacho Fundo 2, no trajeto antes de entrar no eixo sul.

Além disso, foi escolhido não conectar a linha do Recanto e Riacho com a do Gama para não sobrecarregar o sistema de entrada e saída de veículos no mesmo corredor e, 
entendendo também, que o transporte entre essas regiões podem ser supridos através do uso do ônibus.

Por fim, a região central do $\mathrm{DF}$, recebe todos os corredores propostos até o momento. $\mathrm{O}$ planejamento foi idealizado na intenção de conectar todas as linhas através de dois pontos centrais, a rodoviária do Plano Piloto e a antiga Rodoferroviária. Os dois pontos foram conectados por uma nova linha que faz todo o trajeto do eixo monumental, servindo exclusivamente como a linha de integração entre os outros corredores. Além disso, houve a expansão da linha do eixo sul para o eixo norte, possibilitando ainda, a conexão com o corredor da região Asa Norte.

Assim, constata-se a importância da expansão e o acesso do transporte público coletivo através do uso do BRT. Sua tecnologia e custo de implantação são mais atrativas e de fácil execução, podendo assim, alcançar maior parte do território e em consequência disso, ter a capacidade de transportar mais pessoas.

\section{Veículo Leve sobre Trilho - VLT}

O VLT é um sistema de transporte público coletivo, construído nas áreas urbanas e tem como principal objetivo o transporte de passageiros de maneira mais segura e estável. Sua funcionalidade é operada com veículos elétricos de média ou alta capacidade de transporte e sua principal vantagem aos demais modais de transporte é a versatilidade, pois, sua estrutura pode circular em vias, túnel, rodovias, áreas próximas a pedestre e parques (PDTT/DF 2018).

Geralmente, a sua operação é realizada de maneira parcialmente segregada (figura 9), podendo dividir vias com outros veículos e pedestres ou, com via própria ou exclusiva. Contudo, essa versatilidade também pode ocasionar influenciam externas como trânsito, mas vale destacar que esta problemática pode ser resolvida com a construção de trechos totalmente segregados de outros modais.

O VLT é um modal de transporte essencial para a pesquisa, pois é um sistema operacional de fácil adaptação sobre o território, alcançando a possibilidade de implantação de transportes em áreas de difícil acesso. Além disso, a velocidade aferida pelo sistema pode ser adequada de acordo com o interesse do desempenho do serviço a ser prestado, podendo assim, ter mais paradas de acesso e ainda tem velocidade e a diminuição do tempo de trajeto percorrido. 
Figura 9: VLT em via compartilhada entre passageiros e carros

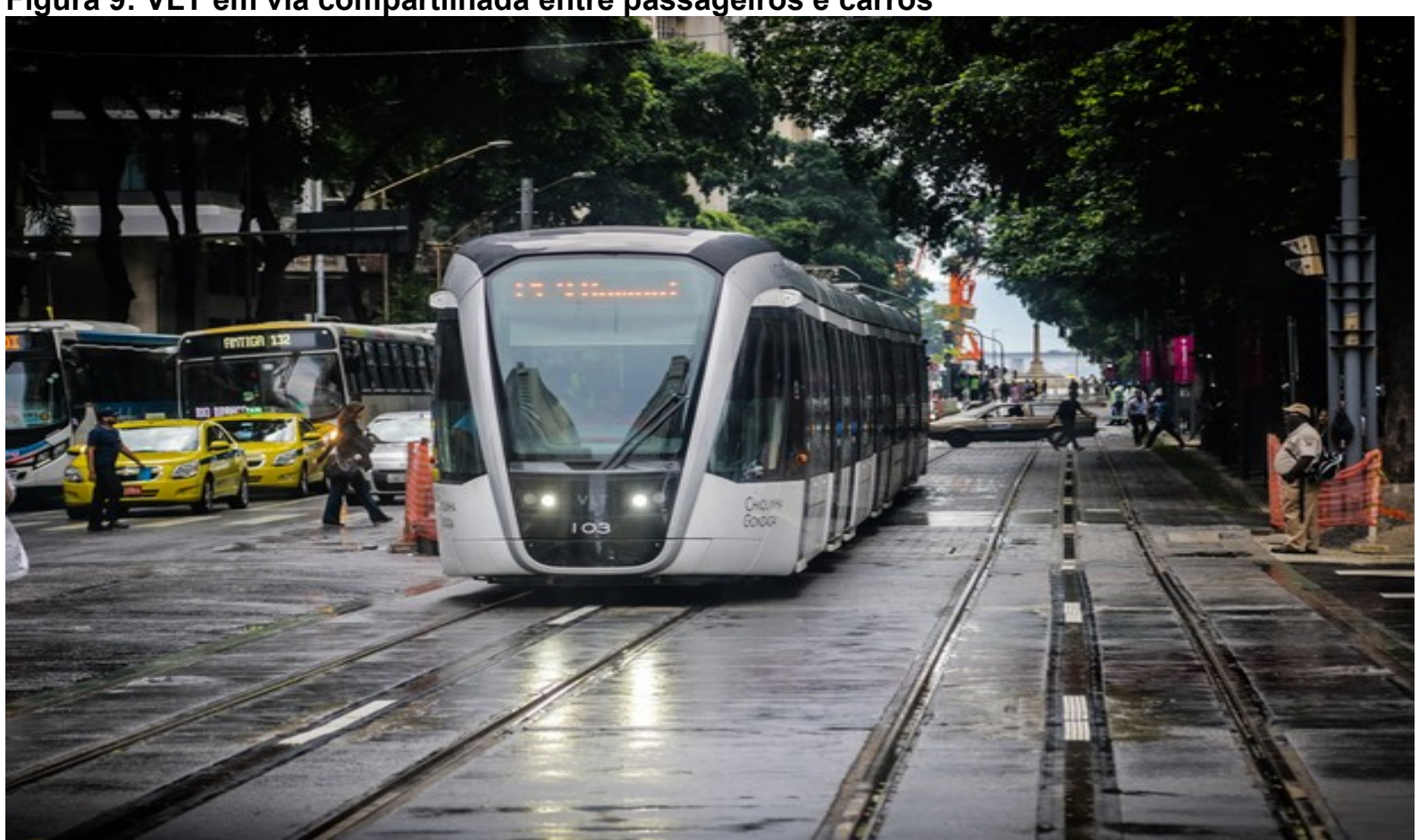

FONTE: Rodrigo Gorosito/G1) 2016

A utilização do VLT para essa proposta se deu de forma específica e direta em regiões onde o BRT não conseguiu alcançar grande influência. Porém, vale destacar que a malha viária que será apresentada não abrange todas as RA's do DF devido ao custo de construção e manutenção desse serviço. Nesse sentido, ao analisar a proposta apresentada pelo PDTT/DF, entendeu-se que o único percurso viário que poderia ser utilizado seria o trajeto Aeroporto W3 Sul. Essa escolha foi embasada no entendimento que parte da proposta já foi contemplada pelo BRT.

Por fim, o mapa a seguir (figura 10), apresenta a proposta de VLT para o DF, presentes na região sudoeste e central da cidade. A proposta apresentada contempla parte do território da região sudoeste, com a linha Ceilândia - Estação Concessionárias e, a região central, com duas linhas, uma sentido Aeroporto - W3 Sul e a outra Rodoviária - UnB.

O planejamento para a região sudoeste se deu através da percepção que esse trajeto poderia aumentar o número da população abrangida por transporte público coletivo. Assim, foi idealizada uma linha de VLT onde teria origem próxima à região do Sol Nascente que abrangeria toda a parte central da Ceilândia, passando pela Avenida Hélio Prates, com recorrente área de engarrafamento e, seguiria sentido pistão norte. A escolha do pistão norte ao invés da comercial ocorreu devido a carência de maior desenvolvimento de transporte público 
se encontra próximo ao pistão, mais especificamente nas áreas sentido Vicente Pires. Por fim, o trajeto final se encontra próximo a estação Concessionárias, em Águas Claras. O intuito dessa escolha foi devido a integração que o VLT poderia ter com o metrô, facilitando assim, o acesso de circulação próximo a linha planejada.

Figura 10: Mapa da proposta de implantação do sistema VLT - DF

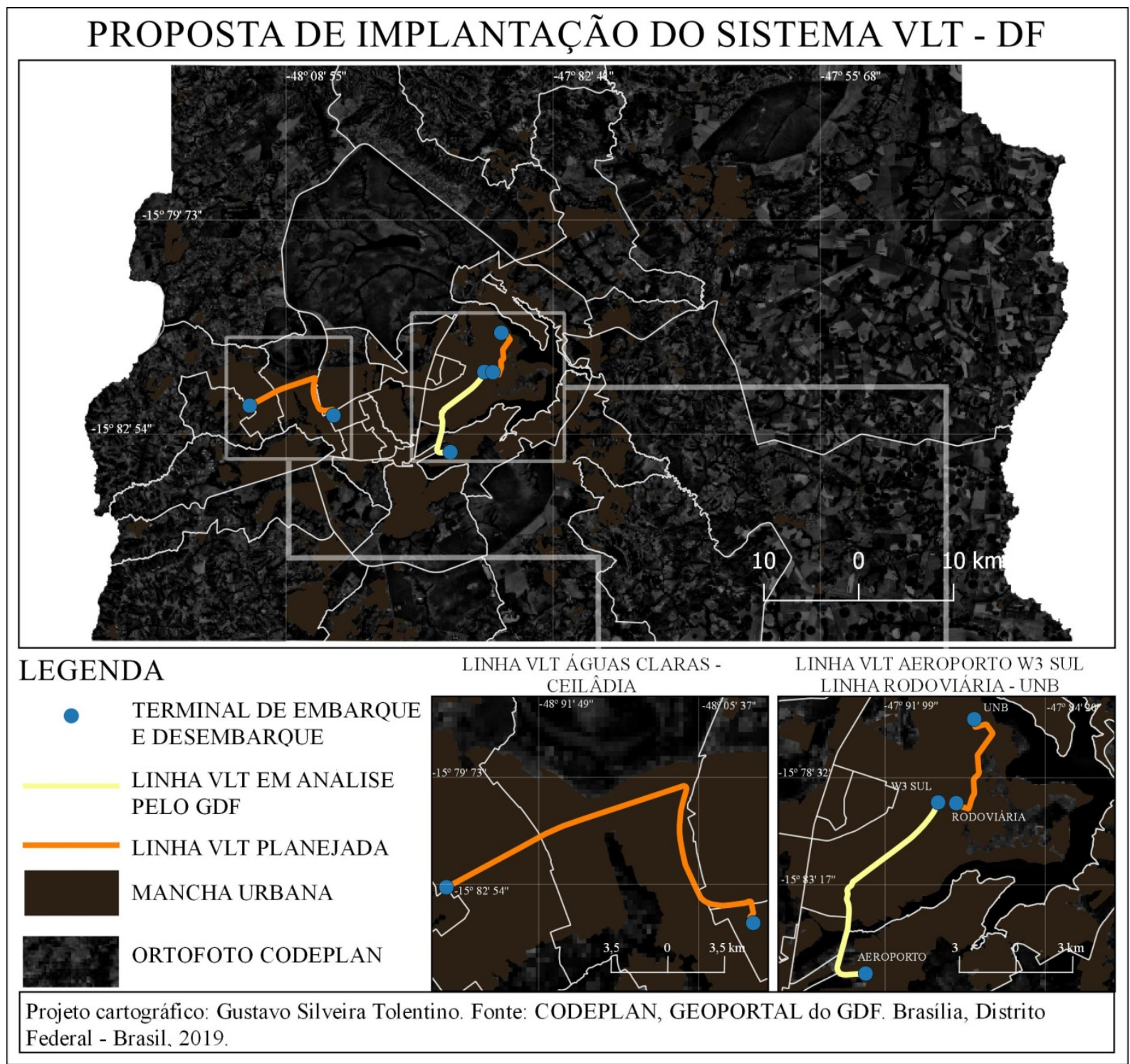

FONTE: GEOPORTAL GDF, CODEPLAN E O AUTOR.

Já região central, consistida por duas linhas de VLT, foi planejada de acordo com o número de circulação de pessoas sobre seu território. Referente ao trajeto Aeroporto - W3 Sul, já apresentado pelo GDF como dito anteriormente, entende-se a importância da sua implantação 
devido aos favorecimentos obtidos para o aeroporto de Brasília e, para a revitalização da W3 Sul. Com isso, a única linha que foi apresentada foi a do trajeto Rodoviária - UnB.

Este pescurso é muito importante, pois a universidade recebe alto número de pessoas que circulam sobre seu campus diariamente. Nesse sentido, a linha apresenta o caminho a partir da rodoviária, passando pela L2 norte e posteriormente adentrando ao Campus Darcy Ribeiro. Já no perímetro da universidade, foi traçado um trajeto diferente da rota de ônibus, passando entre o ICC sul, reitoria, BCE, ICC norte e por fim a colina.

Acredita-se que o sistema do VLT possa ser fundamental para a mobilidade urbana do DF, pois exerce função essencial para a circulação de pessoas sobre áreas de difícil acesso com o BRT ou metrô. Além disso, a praticidade desse serviço em poder trafegar sobre vias e rodovias favorece a sua utilização.

Por fim, o sistema de transporte público apresentado no mapa abaixo (figura 11), é um projeto preliminar com objetivo de melhorar a mobilidade urbana do DF. Percebe-se que os modais apresentados estão espalhados por quase toda a área urbana e, podendo ser alcançada através da integração por intermédio do ônibus. A importância da espacialização de todos os mapas é essencial para a compreensão de um sistema como um todo, sendo necessária a integração entre eles e a possibilidade da população em utilizar mais de um meio de transporte. 
Figura 11: Mapa da proposta preliminar com os modais do BRT, VLT e o metrô PROPOSTA PRELIMAR PARA O SISTEMA DE TRANSPORTE PÚBLICO DO DF

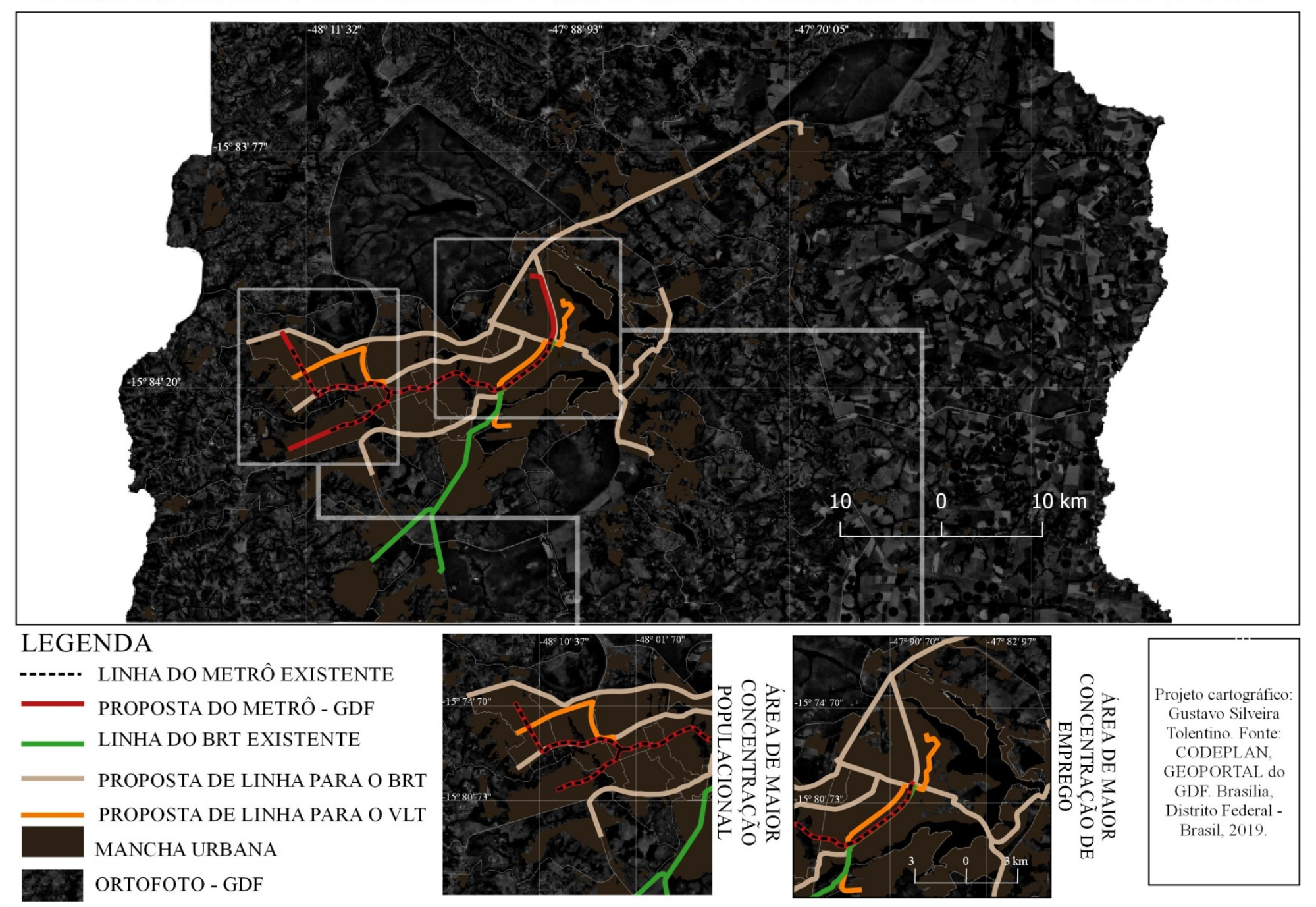

Fonte: PDDTT/DF, Gustavo Tolentino 2019 


\section{Considerações finais}

O transporte se faz peça essencial para a construção e desenvolvimento do espaço urbano na medida em que o dinamiza, tendo em vista sua capacidade de ligar o território. Transformou-se, ao longo da história, de acordo com as necessidades do ser humano, dando maior fluidez ao espaço e ampliando sua capacidade de deslocar populações. Dada a sua importância, a temática da Geografia dos Transportes permite a compreensão de aspectos variados da ação do ser humano no meio.

Em outras palavras, na medida em que o transporte se torna uma das técnicas mais eficazes para realizar a conexão do território, por intermédio de diversos modais e infraestruturas desenvolvidas, é possível enxergar sua interferência e influência social, econômica e geográfica, como foi possível observar historicamente no Brasil pelo panorama levantado.

$\mathrm{Na}$ análise do funcionamento do sistema de transporte do Distrito Federal, foi possível constatar algumas potencialidades e fragilidades, as quais foram consideradas para apresentar propostas preliminares. A época da construção de Brasília foi privilegiada a ideia da cidade do veículo, que sustenta reflexos até a atualidade, visto que culturalmente há uma valorização do transporte privado em detrimento do transporte público, problemática que não se trata de uma exclusividade da realidade do Distrito Federal, mas sim, comum nos grandes centros urbanos.

Isto posto, a esfera pública do transporte urbano adquire uma importância e uma função social ainda maior, por prover o serviço a grandes contingentes populacionais, por vezes de maneira mais acessível. E em razão do acelerado crescimento das cidades que inúmeras problemáticas têm sido geradas, dentre as quais o da mobilidade urbana se destaca, pois nota-se um aumento no uso dos veículos privados saturando as vias. Crescem, portanto, questionamentos sobre como favorecer o desenvolvimento e uso do transporte público coletivo de qualidade, eficiência e agilidade.

Partindo destas ideias, foram alcançadas algumas considerações conclusivas, a partir das quais foram pontuadas recomendações para os atores e agentes que mais influem no desenvolvimento do transporte público do Distrito Federal:

- O transporte público precisa ser considerado como prioridade quando relacionado a dinâmica de circulação sobre o território. Para tanto, entende-se que este progresso é composto tanto pelo GDF, agente determinante, visto que a partir às suas ações que ocorrem sobre o território, como por parte da população e das empresas públicas e privadas. 
Tolentino, G.

- É necessário fortalecer as relações entre os agentes e os autores envolvidos no transporte do DF, tendo em vista o esquivamento de possíveis problemas recorrentes a falta de diálogo durante o processo de planejamento.

- Frisa-se a importância de melhorar a estrutura do sistema do transporte DF. Cabe ao GDF apresentar o desenvolvimento de reformas e possíveis novas propostas para o modo rodoviário e ferroviário. Nesse caso, destaca-se o Governo como principal agente devido a complexibilidade envolvendo o desenvolvimento de projetos sobre a dinâmica urbana da cidade.

- Referente a população, indica-se a importância de assumir a reflexão do seu papel para o transporte coletivo, dando a seriedade de que o sistema é fundado através dos seus interesses e necessidades. Subsequente a isso, é importante desenvolver maior participação nos projetos apresentados, dando características ao que foi proposto, podendo ter papel de decisão e de participação sobre as novas possibilidades de transportes.

- A fiscalização do funcionamento do transporte passa a ser obrigação por parte do GDF e da população, sendo corresponsáveis ao funcionamento destes serviços de acordo com as necessidades expressadas no território.

- No que diz respeito às empresas prestadoras de transporte, é necessário apresentar frequência e pontualidade de seus serviços, tais como a escolha de veículos adequados ao público, trazendo maior conforto e seguranças, no intuito de atrair maior número de usuários ao transporte coletivo.

A partir dos aspectos levantados acima, é relevante ressaltar que a proposta preliminar apresentada é fundada na concepção de um transporte público de qualidade, idealizando a evolução e a prioridade desse meio técnico sobre o território do DF. Para tanto, o desenvolvimento desse progresso requer planejamento de expansão e criação de novos modais que integram as regiões com maior grau de complexibilidade, como mapeado durante o trabalho. Todavia, em contrapartida a idealização de progresso, entende-se as dificuldades e os desafios a serem enfrentados no desenvolvimento de propostas preliminares para o transporte público devido a complexibilidade intrínseca nas ações do espaço urbano.

Nesta perspectiva, entende-se que é importante que a questão dos transportes esteja em pauta, tendo em vista sua imprescindibilidade para as práticas humanas, que acontecem no espaço. É neste contexto que a Geografia pode apresentar suas contribuições no âmbito científico, desenvolvendo estudos 
na área, e consequentemente, pensando e alinhando propostas para que se avance o plano dos questionamentos.

Porém, enquanto a Geografia se limita a analisar o transporte de forma secundária, outras áreas do conhecimento estão abordando novas formas de conectar territórios longínquos por meio do transporte aéreo, ferroviário e rodoviário. Claro, esse aspecto comparativo não é no sentido de competição, mas no entendimento que o pensamento geográfico poderia se atentar mais às questões dos transportes devido a sua influência no espaço e suas relações por meio do território. O campo da Geografia dos Transportes necessita ter um maior desenvolvimento e valorização, rompendo com base positivista, oriunda da Geografia da Circulação, e assumindo centralidade e protagonismo nas pesquisas que envolvem as territorialidades, compreendendo suas as múltiplas escalas que abrangem o Brasil.

\section{Bibliografia}

AGÊNCIA BRASÍLIA. Proposta de consórcio para integrar transporte é apresentada em reunião no Entorno. Disponível em: https://www.agenciabrasilia.df.gov.br/2019/08/22/proposta-de-consorcio-para-integrar-transporte-eapresentada-em-reuniao-no-entorno/ Acesso em: 24 de setembro de 2019.

AGÊNCIA BRASÍLIA. GDF analisa propostas de empresas interessadas na operação do VLT em Brasília. Disponível em: https://www.agenciabrasilia.df.gov.br/2019/08/01/gdf-analisa-propostas-de-empresas-interessadas-na-operacao-do-vltem-brasilia/ Acesso em: 24 de setembro de 2019.

ANJOS, R. S. A. Modelagem dos processos espaciais formadores da dinâmica urbana no Distrito Federal do Brasil. 1995.

ANJOS, R. S. A. Dinâmica Territorial: Cartografia -Monitoramento-Modelagem. Brasília: Mapas Editora e Consultoria, 2008.

BERNARDES, Adriana, Niederauer, M. DF sobre trilhos. Disponível em: http://especiais.correiobraziliense.com.br/dfsobre-trilhos/ Acesso em: 03 de janeiro de 2019.

BRANDÃO, Ana Rute Pinto. A postura do positivismo com relação as ciências humanas. Theoria Revista Eletrônica de Filosofia, Pouso Alegre, MG, v. 3, n. 6, p. 80-105, 2011.

CAMPOS, V. B. Planejamento de transportes: Conceitos e modelos. $1^{\text {a }}$ ed. - Rio de Janeiro: Interciência, 2013.

CARDIM, Nathália. Faixas exclusivas liberadas após estações do metrô serem fechadas. Disponível em:

https://www.metropoles.com/distrito-federal/faixas-exclusivas-da-epnb-sao-liberadas-apos-metro-ficar-fechado/ Acesso em: 10 de novembro de 2019.

CARDIM, Nathália. DF: após falha, Metrô anuncia reabertura das estações. Disponível em: https://www.metropoles.com/distrito-federal/transporte-df/com-falha-de-sinalizacao-metro-df-amanhece-com-estacoesfechadas/ Acesso em: 10 de novembro de 2019.

CASTILHO, D. Modernização Territorial e Redes Técnicas em Goiás. Tese de Doutorado. Universidade Federal de Goiás - IESA. Goiânia, 2014.

CASTRO, I. E. Geografia: Conceitos e Temas, org. I. E. Castro, P. C. C. Gomes e R. L. Côrrea, $16^{\text {a }}$ ed. - Rio de Janeiro, Bertrand Brasil, 2014.

COMPANHIA de Planejamento do Distrito Federal (Codeplan). Demografia Em Foco. Evolução dos Movimentos Migratórios para o Distrito Federal: 1959-2010. Disponível em: $<$ https: //goo.gl/e2epAs $>$. Acesso em 10 de maio de 2018.

COMPANHIA de Planejamento do Distrito Federal (Codeplan). Expansão da Linha 1 do Metrô-DF - Diagnóstico Urbano da Área de Influência Direta. Nota Técnica | DIEPS - Codeplan | Dezembro 2018.

COSTA, António Gilberto (coord.). Roteiro Prático de Cartografia: da América Portuguesa ao Brasil Império, Universidade Federal de Minas Gerais, Belo Horizonte, 2007.

Revista Eletrônica: Tempo - Técnica - Território, V.10, N.2 (2019), 54:80 - ISSN: 2177-4366 
G1. Rio tem o pior sistema de transportes entre 74 cidades do mundo, diz estudo. Disponível em:

https://g1.globo.com/rj/rio-de-janeiro/noticia/rio-tem-o-pior-sistema-de-transportes-entre-74-cidades-do-mundo-dizestudo.ghtml/ Acesso em: 18 de agosto de 2018.

G1. Mais de 400 linhas de ônibus do DF mudam durante férias escolares. Disponível em:

https:/g1.globo.com/df/distrito-federal/noticia/mais-de-400-linhas-de-onibus-do-df-mudam-durante-ferias-escolares.ghtml/ Acesso em: 18 de agosto de 2018.

GIL, A. C. Métodos e técnicas de pesquisa social. São Paulo: Atlas, 1999.

HUERTAS, Daniel Monteiro. Território e Circulação: Transporte rodoviário de carga no Brasil. Tese (Doutorado em Geografia Humana) - Faculdade de Filosofia, Letras e Ciências Humanas, Universidade de São Paulo, São Paulo, 2013. IANSEN, M. Como os indígenas do Brasil faziam canoas. Disponível em:

https://martaiansen.blogspot.com/2014/10/como-os-indigenas-do-brasil-faziam-canoas.html/ Acesso em: 15 de maio de 2018.

IBGE - Atlas nacional de comércio e serviços [material cartográfico]. - Escalas diferem. - Brasília, DF: MDIC, 2013. KUBISTCHECK, Juscelino. Porque construí Brasília. Brasília: Senado Federal, Conselho Editorial, 2000.

LA BLACHE, Vidal de. Princípios de Geografia Humana. 2a ed. rev. Lisboa (Portugal): Edições Cosmos, 1954 ( $1^{\mathrm{a}}$ ed. original: Paris, 1921).

LAMOUNIER, Maria Lúcia. Ferrovias e Mercado de Trabalho no Brasil do Século XIX. São Paulo, Editora da Universidade de São Paulo, 2012.

LOBO, Renato. China vai construir novo trem de alta velocidade entre Chongqing - Kunming. Disponível em: https://viatrolebus.com.br/2019/09/china-vai-construir-novo-trem-de-alta-velocidade-entre-chongqing-kunming/ Acesso em: 15 de setembro de 2019.

MACÁRIO, Igor, Lasco, T. Moto pode circular no corredor urbano. Disponível em:

https://jornaldocarro.estadao.com.br/motos/moto-pode-circular-no-corredor-urbano/ Acesso em: 20 de fevereiro de 2018.

MARQUES, P. C. Entrevista concedida a Dayana Hashim. Darcy, Brasília. n. 18, p 12-17, março a maio de 2018.

MENDES, Helen. Um terço das ferrovias do país foi construído no Brasil Imperial. Disponível em:

https://www.gazetadopovo.com.br/ideias/um-terco-das-ferrovias-do-pais-foi-construido-no-brasil-imperial-

0g3olihyllr66ezetyly591ld/ Acesso em: 01 de julho de 2018.

METRÔ DF. PDTT - DF. Disponível em: https: //wwwmetro.df.gov.br/ Acesso em 20 de novembro de 2019.

PAVIANI, A. (org.) Brasília: moradia e exclusão. Coleção Brasília. Brasília, Editora UnB, 1996.

PAVIANI, A.(org.) A Conquista da Cidade. 2 ed. Brasília, Editora da UnB, 1998.

PEREIRA, V. B. Transportes: história, crises e caminhos. Rio de Janeiro: Civilização Brasileira, 2014.

SANTOS, M. O Espaço Dividido. São Paulo, Francisco Alves, 1979.

SANTOS, M. A natureza do espaço. São Paulo: Edusp, 2002 [1996].

SANTOS, M. Silveira, M. L. O Brasil: Território e Sociedade no início do século 21. 19ª ed. - Rio de Janeiro: Record, 2016.

SECRETARIA de Estado de Desenvolvimento Urbano e Habitação. Plano Diretor de Ordenamento Territorial do

Distrito Federal - PDOT. Disponível em: http://www.seduh.df.gov.br/plano-diretor-de-ordenamento-territorial/ Acesso em 27 de outubro de 2019.

SECRETARIA de Transporte e Mobilidade. GDF quer aumentar em 17\% o número de usuários do transporte público. Disponível em: http://www.semob.df.gov.br/gdf-quer-aumentar-em-17-o-numero-de-usuarios-do-transporte-publico/

Acesso em: 30 de setembro de 2019.

SECRETARIA de Transporte e Mobilidade. Linhas de ônibus passam por readequação nas férias escolares. Disponível em: http://www.semob.df.gov.br/linhas-de-onibus-passam-por-readequacao-nas-ferias-escolares/ Acesso em: $30 \mathrm{de}$ setembro de 2019.

SENNA, L. A. S. Economia e planejamento dos transportes 1. ed. - Rio de Janeiro : Elsevier, 2014.

SILVA JÚNIOR, Roberto França da. Circulação e logística territorial: a instância do espaço e a circulação

corporativa. 2009. 358 f. Tese (doutorado) - Universidade Estadual Paulista, Faculdade de Ciências e Tecnologia, 2009.

SILVEIRA, M. R (Org). Circulação, Transportes e Logística: Diferentes Perspectivas. 1. ed. São Paulo: Outras Expressões, 2011.

TACO, P. W. G, Sousa A. M, Silva P. B. Acessibilidade e mobilidade urbana na perspectiva da equidade e inclusão social. Goiânia: Kelps; 2018. 